\title{
Adenoviral-Induced Islet Cell Cytotoxicity Is Not Counteracted by Bcl-2 Overexpression
}

\author{
Andreea R. Barbu, ${ }^{1}$ Göran Akusjärvi, ${ }^{2}$ and Nils Welsh ${ }^{1}$ \\ ${ }^{1}$ Department of Medical Cell Biology, Uppsala University, Uppsala, Sweden \\ ${ }^{2}$ Department of Medical Biochemistry and Microbiology, Uppsala University, Uppsala, Sweden \\ Accepter September 11, 2002
}

\begin{abstract}
Background: The ability to transfer immunoregulatory, cytoprotective, or anti-apoptotic genes into pancreatic islet cells may allow enhanced resistance against the autoimmune destruction of these cells in type 1 diabetes. We describe here an inducible transduction system for expression of the anti-apoptotic bcl-2 gene in insulin-producing cells as a potential tool for protecting against $\beta$-cell death. Materials and Methods: Isolated pancreatic rat islet cells or rat insulinoma (RINm5F) cells were transduced using a progesterone antagonist (RU 486) inducible adenoviral vector system, expressing the bcl-2 gene. Bcl-2 overexpression was measured by Western blot assays and flow cytometry analysis. Following exposure to cytokines or to the mitochondrial uncoupler FCCP, cell survival was determined using fluorescence and electron microscopy, and a colorimetric assay (2,3-bis[2-methoxy-4-nitro-5-sulfophenyl]$2 H$-tetrazolium-5-carboxanilide [XTT]-based) for cell viability. The mitochondrial membrane potential $\left(\Delta \Psi_{\mathrm{m}}\right)$ was assessed using the lipophilic cationic membrane potential-sensitive dye JC-1.
\end{abstract}

Results: The adenoviral gene transfer system induced Bcl-2 expression in more than $70 \%$ of $\beta$-cells and the protein expression levels were successfully regulated in response to varying concentrations of progesterone antagonist RU 486. Exposure of islet cells to proinflammatory cytokines IL- $1 \beta$, TNF- $\alpha$, and IFN- $\gamma$, or to the mitochondrial uncoupler FCCP resulted in disruption of the mitochondrial membrane potential $\left(\Delta \Psi_{\mathrm{m}}\right)$ and $\beta$-cell death. Bcl-2 overexpression stabilized $\Delta \Psi_{\mathrm{m}}$ and prevented cell death in RINm5F cells but not in islet cells. In addition, prolonged in vitro culture revealed adenoviral-induced islet cell necrosis.

Conclusions: The RU 486-regulated adenoviral system can achieve an efficient control of gene transfer at relatively low doses of the adenoviral vector. However, Bcl-2 overexpression in islet cells did not prevent adenoviral- or cytokine-induced toxicity, suggesting that the specific death pathway involved in adenoviral toxicity in $\beta$-cells may bypass the mitochondrial permeability transition event.

\section{Introduction}

Insulin-dependent (type 1) diabetes mellitus is an autoimmune disorder resulting from the specific and progressive destruction of insulin-producing $\beta$-cells of the islets of Langherhans. Dysfunction and damage of $\beta$-cells in the early phase of the disease is thought to result from a direct contact with isletinfiltrating cells (macrophages, $\mathrm{CD}^{+}{ }^{+} \mathrm{T}$ cells, $\mathrm{CD} 8^{+}$ $\mathrm{T}$ cells) and/or exposure to cytotoxic mediators produced by these cells $(1,2)$, leading to $\beta$-cell death both by apoptosis (3) and necrosis (4).

It has been shown that several apoptotic and necrotic pathways share a mitochondrial rate-limiting step: the mitochondrial permeability transition (MPT) (5). Previous studies indicated that proteins belonging to the Bcl-2 family are ubiquitous regulators of cell death acting primarily at the mitochondrial level of the death pathway. The anti-apoptotic protein Bcl-2 in particular is able to modulate the release of apoptogenic factors (cytochrome $\mathrm{c}$ and AIF)

Address correspondence and reprint requests to: Andreea Barbu, Department of Medical Cell Biology, Biomedical Center, PO Box 571, S-751 23 Uppsala, Sweden. Phone: +46 1847143 95; fax: +46 185564 01; e-mail: Andreea.Barbu@medcellbiol.uu.se.
$(6,7)$ as well as to inhibit the mitochondrial membrane depolarization (8). Bcl-2 overexpression has been reported to prevent cellular death both by apoptosis (5) and necrosis (4) in many cell types including insulin-producing cells, suggesting its potential as a tool for gene therapy in type 1 diabetes.

Efficient techniques for gene transfer can lead to successful manipulation of primary $\beta$-cells to resist autoimmune-mediated destruction and to allow enhanced posttransplantation survival of islets grafts. Recent studies reported efficient transduction of insulin-producing cells using lentivirus $(9,10)$ and adeno-associated virus (11) vectors. To date, though, replication-deficient adenoviruses are the most commonly used in $\beta$-cell research and they have been shown to successfully transduce pancreatic insulinproducing cells isolated from rat, mouse $(12,13)$, monkey (14), and pig pancreas (15). In this context, newly developed inducible adenoviral systems permitting regulated protein expression may play a valuable role both in understanding the molecular mechanisms of the pathogenesis of type 1 diabetes as well as in prevention and treatment of the disease.

The purpose of this study was to characterize the progesterone antagonist (RU 486)-inducible adenoviral 
system (16) for expression of the anti-apoptotic bcl-2 gene in insulin-producing cells as a potential tool for protecting against pancreatic $\beta$-cell death in type 1 diabetes.

\section{Materials and Methods Materials}

The reagents were purchased from the following companies: culture medium RPMI 1640, Fetal Calf Serum (FCS), L-glutamine, penicillin, and streptomycin, trypsin-EDTA, carbonil cyanide $p$-trifluoromethoxyphenyl-hydrazone (FCCP), bisbenzimide (Hoechst 33342), and propidium iodide from Sigma (St. Louis, MO, USA); recombinant mouse interleukin (IL)- $1 \beta$, recombinant mouse tumor necrosis factor alpha (TNF- $\alpha$ ), and recombinant mouse interferon gamma (IFN)- $\gamma$ from PeproTech (London, UK). All other chemicals of analytical grade were obtained from E. Merk (Darmstadt, Germany).

\section{Cell Culture}

RINm5F cells were trypsinized every 3 days and subcultured $\left(5 \times 10^{5}\right.$ cells per $50-\mathrm{mm}$ well $)$ in RPMI 1640 supplemented with $10 \%$ FCS, 2 mM L-glutamine, benzylpenicillin $(100 \mathrm{U} / \mathrm{ml})$, and streptomycin $(0.1 \mathrm{mg} / \mathrm{ml})$ at $37{ }^{\circ} \mathrm{C}$ in humidified air with $5 \% \mathrm{CO}_{2}$. Rat islets were isolated from 3-month-old Sprague-Dawley rats (local Uppsala colony), as previous described (17). Islets were cultured in groups of 150 per $50-\mathrm{mm}$ well under the conditions described for 3-5 days before experiments.

\section{Adenoviral Vector Construct and Gene Transfer}

RU 486-induced gene expression system was constructed as previously described (16). This adenovirus vector system makes use of a doubleinfection strategy to control gene expression. Briefly, a chimeric transactivator protein consisting of the ligand-binding domain of hPRB89l fused to the Gal4 DNA binding domain and the herpes simplex virus VP16 transactivator domain was cloned behind a cytomegalovirus (CMV) promotor and inserted into an adenovirus type 5 (Ad5)dl309 vector, generating the virus AdCMVProg (16). The murine bcl-2 gene, kindly provided by Dr. E. Podack (Miami, FL, USA), was cloned as a BamHI fragment behind a Gal4 enhancer, consisting of five Gal4 DNA-binding sites fused to a minimal major late promotor/tripartite leader construct, generating the virus AdG5TripBcl-2. The bcl-2 insert was control sequenced using the following primers (Cybergene $\mathrm{AB}$, Hudinge Sweden):

$$
\begin{aligned}
& \text {-5' GGCGTCTAACCAGTCACAGTCGCAA3' (sense) } \\
& \text {-5'AGATGTCACCCCTGGTGGACAACAT3' (antisense) }
\end{aligned}
$$

Transcription of the bcl-2 gene is activated by the addition of the progesterone antagonist RU 468 to the culture medium.
Before transduction, rat islets were dispersed into individual cells by treatment with trypsin $(5 \mathrm{mg} / \mathrm{ml})$ in $\mathrm{Ca}^{2+}$ - and $\mathrm{Mg}^{2+}$-free Hanks solution at $37^{\circ} \mathrm{C}$ for $5 \mathrm{~min}$ and then cultured for an additional hour. Single cells from dispersed islets or RINm5F cells were washed in RPMI 1640 medium supplemented with $2 \%$ FCS, and then infected at different $\mathrm{PFU} /$ cell for $1 \mathrm{hr}$ in a minimum volume of $0.5 \mathrm{ml}$ at $37{ }^{\circ} \mathrm{C}$. After infection, cells were washed with complete RPMI 1640 medium and cultured in the presence or the absence of RU 486 for 1-7 or 30 days before being tested for $\mathrm{Bcl}-2$ expression and cell viability or used for further experiments.

\section{Assessment of Transfection Efficiency}

Transgene expression was assessed by Western blot analysis. At different time points after transfection, $\beta$-cells from dispersed islets or RINm5F cells were washed with cold phosphate-buffered saline (PBS), briefly sonicated in SDS sample buffer (containing $\beta$-mercaptoethanol), and subjected to Western blot analysis. The membranes were incubated with mouse anti Bcl-2 antibody (Transduction Laboratory). Horseradish peroxidase-linked sheep anti-mouse immunoglobulin (Ig) was used as a secondary antibody, and immunoreactivity was subsequently detected by ECL.

For the quantitative determination of the transduction efficiency, we used flow cytometric analysis. Twenty-four or 48 hours after transfection RINm5F cells and pancreatic $\beta$-cells were washed with cold PBS and fixated for 5 min in PBS $+4 \%$ paraformaldehyde, followed by an additional washing and incubation for $10 \mathrm{~min}$ at room temperature in PBS + $1 \%$ FCS and $0.1 \%$ saponin. Cells were then incubated in PBS $+1 \%$ FCS $+0.1 \%$ saponin solution containing rabbit anti-Bcl-2 (Santa Cruz Biotechnology, Santa Cruz, CA, USA) and guinea pig antiinsulin (ICN Biomedicals, Aurora, OH, USA) antibodies for $1 \mathrm{hr}$ at room temperature, washed, and further incubated with fluorescent secondary antibodies, fluorescein (FITC)-conjugated AffiniPure donkey anti-rabbit IgG and R-Phycoerythrinconjugated AffiniPure donkey anti-guinea pig IgG (Jackson ImmunoResearch Laboratories). The cells were then analyzed with a FACSCalibur flow cytometer (Becton-Dickinson, Oxford, UK). Fluorescence emissions from FITC-positive cells (Bcl-2 overexpressing cells) and R-Phycoerythrin-positive cells (insulin-producing cells) were detected at a wavelength of $530 \mathrm{~nm}$ and $590 \mathrm{~nm}$, respectively. Data were analyzed using CellQuest software (Becton-Dickinson).

\section{Assessment of $\beta$-Cell Viability}

Adenoviral-induced cellular death was assessed using the colorimetric assay (XTT-based) for cell viability. This assay is based on the conversion of the tetrazolium salt XTT into an orange-red colored formazan product by mitochondrial enzymes. 
Adenoviral-transduced and nontransduced cells were plated in 96-well plates in $100 \mu$ l complete culture medium RPMI 1640 containing 10\% FCS. Cell viability was determined 7 days after transduction by adding $50 \mu \mathrm{l}$ of $1 \mathrm{mg} / \mathrm{ml}$ XTT solution (Sigma) to each well. The plates were then incubated at $37^{\circ} \mathrm{C}$ for $3 \mathrm{hr}$ and the optical densities were read in a Microplate autoreader (Bio-Tek Instruments) at $490 \mathrm{~nm}$. FCCP-induced cell death was assessed after 1 day of treatment by XTT assay as described. After 1 or 6 days of exposure to cytokines (IL- $1 \beta, 25 \mathrm{U} / \mathrm{ml}$; TNF- $\alpha, 1000 \mathrm{U} / \mathrm{ml}$; and IFN- $\gamma, 1000$ $\mathrm{U} / \mathrm{ml}), \mathrm{RINm} 5 \mathrm{~F}$ cells or islet cells were incubated in culture medium containing $20 \mu \mathrm{g} / \mathrm{ml}$ bisbenzimide and $10 \mu \mathrm{g} / \mathrm{ml}$ propidium iodide for $20 \mathrm{~min}$ at $37^{\circ} \mathrm{C}$ as described (18). Cells were then washed with PBS and examined by fluorescence microscopy using a UV-2A or a B-2A filter.

\section{Determination of the Mitochondrial Membrane} Potential $\left(\Delta \Psi_{m}\right)$ by JC-1 Fluorescence

The mitochondrial membrane potential was semiquantitatively determined using the fluorescent probe JC-1. Briefly, transduced and nontransduced RINm5F cells and rat islet cells were exposed to cytokines (IL- $1 \beta, 25 \mathrm{U} / \mathrm{ml}$; IFN- $\gamma, 1000 \mathrm{U} / \mathrm{ml}$; and TNF$\alpha, 1000 \mathrm{U} / \mathrm{ml}$ ) or to the mitochondrial uncoupler FCCP $(5 \mu \mathrm{M})$ for $24 \mathrm{hr}$ and then incubated in culture medium containing $10 \mu \mathrm{M} \mathrm{JC}-1$ (solubilized in $\mathrm{N}, \mathrm{N}$ dimethylformamide, $1 \% \mathrm{v} / \mathrm{v}$ ) for $30 \mathrm{~min}$ at $37{ }^{\circ} \mathrm{C}$. Cells were then washed and trypsinized, followed by flow cytometric analysis. Photomultiplier settings were adjusted to detect JC-1 monomers and Jaggregates fluorescence on the FL1 $(530 \mathrm{~nm})$ and FL2 $(585 \mathrm{~nm})$ detectors, respectively. The fluorescence ratio at those wavelengths was used to monitor changes in mitochondrial membrane potential (19).

\section{Electron Microscopy Studies}

Dispersed rat islets were infected with $30 \mathrm{PFU} / \mathrm{cell}$ of the adenoviral vector (AdProgCMV) for $60 \mathrm{~min}$, and further cultured for 7 days. Uninfected dispersed islets were used as controls. The cells were fixed with glutaraldehyde $(2.5 \%$ in $0.1 \mathrm{M}$ cacodylate buffer, pH 7.4) for $30 \mathrm{~min}$, dehydrated in an ethanol series, and then infiltrated with absolute ethanol containing increasing concentrations of Agar 100 Resin (Agar Scientific, Stansted, UK). The resin was polymerized for 2 days at $60^{\circ} \mathrm{C}$. Sections were cut, contrasted with uranyl acetate and lead citrate, and examined and photographed with a Hitachi H-7100 transmission electron microscope at $75 \mathrm{kV}$.

\section{Statistical Analysis}

Results are presented as means \pm SEM. The statistical differences between the groups are determined by one-way analysis of variance (ANOVA) for repeated measurements and the Bonferroni test. All statistical analyses were performed using Sigmastat (SPSS Science Software, Erkrath, Germany).

\section{Results \\ Inducible Adenoviral-Mediated bcl-2 Gene Transfer into RINm5F Cells and Dispersed Rat Islet $\beta$-Cells}

To test the induction potential of adenoviral RU 486regulated system for the expression of $\mathrm{Bcl}-2$ in insulin-producing cells, RINm5F cells, and single cells from rat islets were infected with different concentrations of the viruses $(1,10,100$, and 1000 $\mathrm{PFU} /$ cell). Dispersed rat islet cells were used because we observed low transduction efficiency when attempting to transduce precultured intact islets (results not shown). The bcl-2 gene expression was induced immediately after infection by addition of varying amounts of the inducer (the progesterone antagonist RU 486). Detection of protein expression was performed by Western blot analysis. As shown in Fig. la., Bcl-2 expression was undetectable in uninduced RINm5F cells. Transcriptional activation in response to RU 486 administration was sensitive to concentrations of drugs as low as $0.01 \mathrm{nM}$ with maximal induction being reached at $0.1 \mathrm{nM}$ (Fig. la). Expression of Bcl-2 protein was completely lost 1 week after transfection (Fig. la). As expected, increasing concentrations of the virus (PFU/cell) resulted in a corresponding increase of protein expression levels (Fig. la). The same dose-response curve was observed in the tested range of 1-1000 PFU/cell in dispersed rat islets, although with a low basal transcription of bcl-2 gene in the absence of the inducer (Fig. lb). In single islet cells, a maximal induction of Bcl-2 production was observed 2 days after transfection and this level of protein expression was not diminished at 7 days posttransfection. Additional experiments showed that protein expression was maintained at similar levels even 1 month after transfection (Fig. 1b).

To assess the percentage of cells overexpressing Bcl-2, RINm5F cells and dispersed islet cells were infected with $30 \mathrm{PFU} / \mathrm{cell}$ of RU 486-inducible adenoviral system, and stained with anti-insulin and anti-Bcl-2 antibodies. In a typical experiment, more than $45 \%$ of RINm5F cells and more than $70 \%$ of $\beta$ cells from dispersed islets were overexpressing the anti-apoptotic Bcl-2 protein, as shown by flow cytometric analysis (Fig. Ic). Thus, efficient, long-term, and inducible expression of $\mathrm{Bcl}-2$ can be achieved in rat islet cells.

\section{Effect of Bcl-2 Overexpression on Cytokine- and FCCP-Induced Cell Death in RINm5F Cells}

In a first evaluation of the protective effect of Bcl-2 overexpression against RINm5F cell death, we exposed transduced and nontransduced cells to a combination of IL-1 $\beta$, TNF- $\alpha$, and IFN- $\gamma$. Subsequently, cells were stained with bisbenzimide/propidium iodide and examined by fluorescence microscopy. A $24 \mathrm{hr}$ exposure to cytokines resulted in a significantly decreased survival in both nontransduced 
(a)

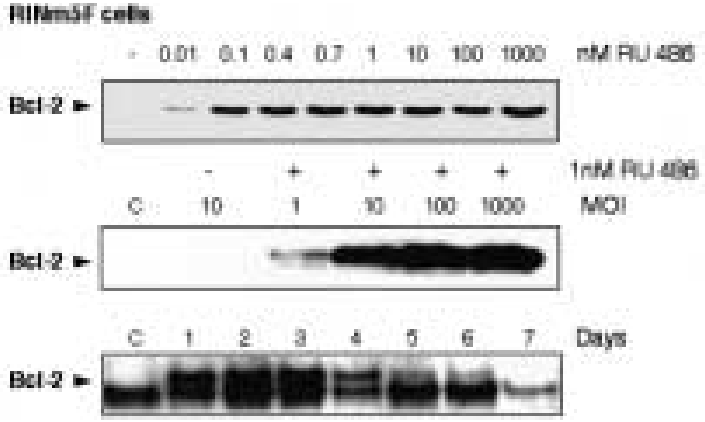

(b)

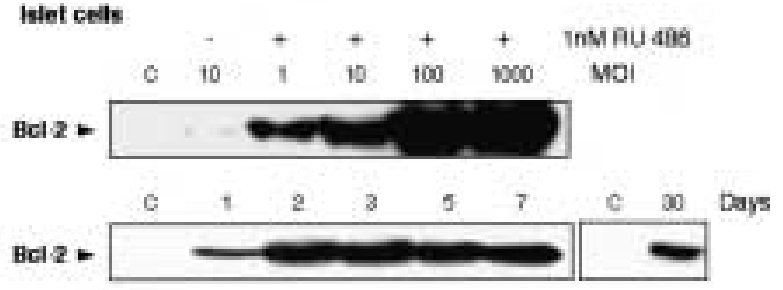

(e)
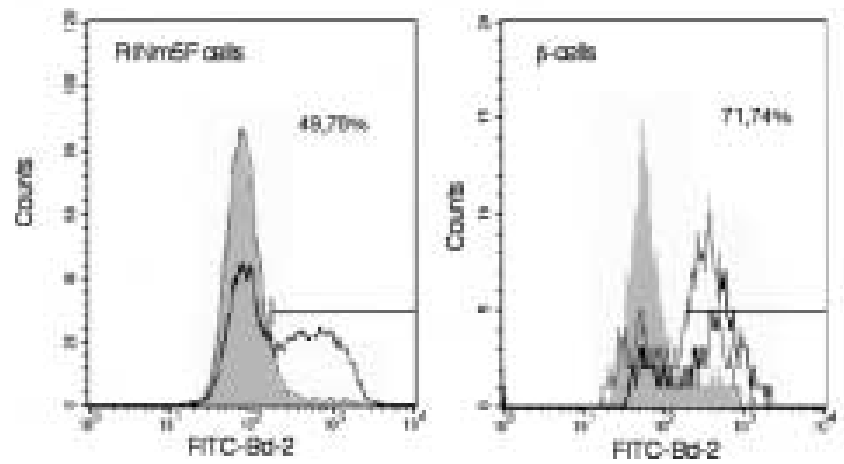

Fig. 1. Expression of Bcl-2 gene in RINm5F cells (a) and pancreatic islet cells (b), and determination of the transduction efficiency (c). (a and b) Cells were incubated at $37^{\circ} \mathrm{C}$ for $60 \mathrm{~min}$ with different concentrations of adenoviruses. bcl-2 gene expression was induced immediately after infection with different amounts of RU 486. One to 7 or 30 days after transduction, cell lysates were analyzed by Western blot for the expression of Bcl-2 as described in Methods. (c) RINm5F cells (left panel) and islet cells (right panel) were incubated for $60 \mathrm{~min}$ in the presence of $30 \mathrm{PFU} / \mathrm{cell}$ AdCMVProg and AdG5Trip-Bcl2 and gene expression was induced immediately after infection with InM RU 486. Twenty-four hours (RINm5F cells) or $48 \mathrm{hr}$ (islet cells) after transduction cells were stained for insulin and for Bcl-2 expression as described in Methods and analyzed by flow cytometry. Nontransduced cells (filled histogram), transduced but not induced cells (gray histogram), transduced and induced cells (black histogram).

and transduced-but-not-induced RINm5F cells (Fig. 2a) and our results indicate that the main form of cell death was necrosis. Bcl-2 expression completely inhibited cytokine-induced cellular death in RINm5F cells (Fig. 2a).

Because mitochondrial uncoupling was shown to be a potential trigger for the initiation of both apotosis and necrosis (5), we next tested whether (a)

\section{AIRm5F cells}

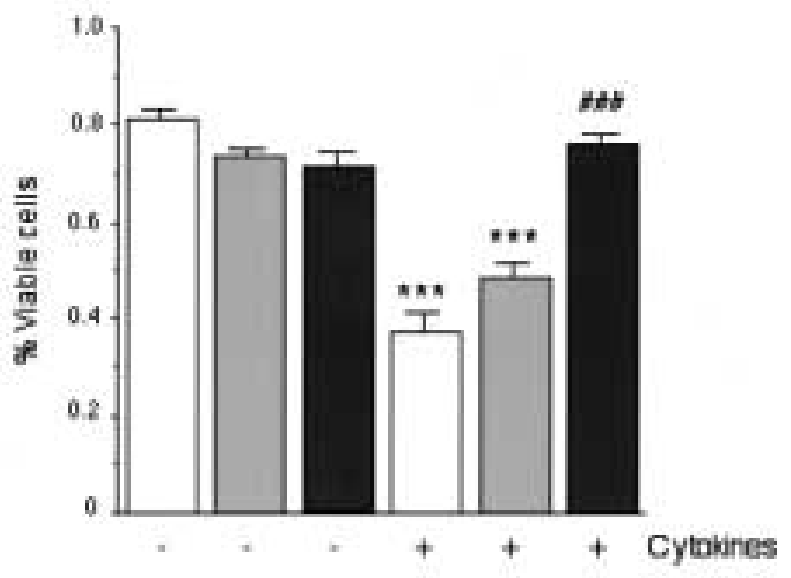

(b)

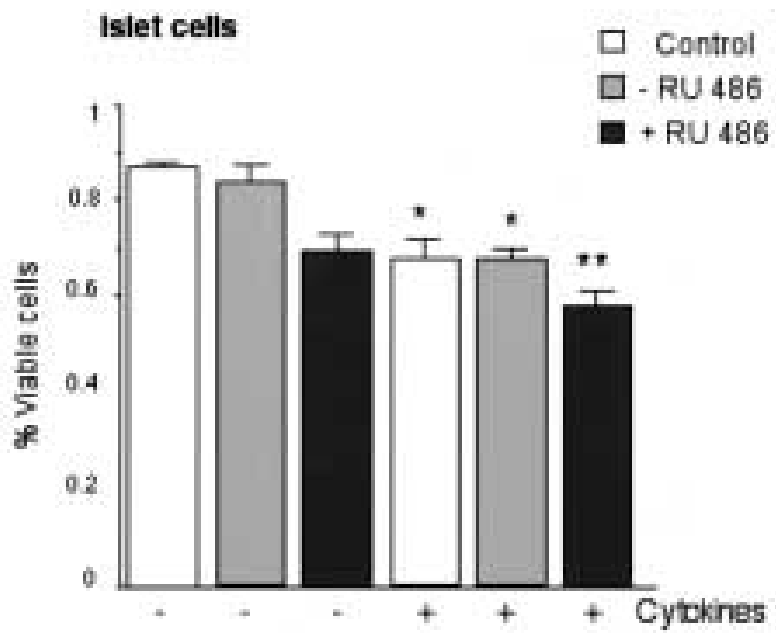

Fig. 2. Cytokine-induced cell death and the effect of Bcl-2 expression in RINm5F cells (a) and pancreatic islet cells (b). Transduced (13 PFU/cell) and nontransduced cells were exposed for 1 day (RINm5F cells) or 6 days (islet cells) to the combination IL-1 $\beta(25 \mathrm{U} / \mathrm{ml}), \mathrm{TNF}-\alpha(1000 \mathrm{U} / \mathrm{ml})$, and IFN- $\gamma$ $(1000 \mathrm{U} / \mathrm{ml})$ followed by staining with bisbenzimide/propidium iodide and fluorescence microscopy. Results are mean \pm SEM for four separate experiments. ${ }^{* * *} p<0.001$ when comparing versus nontransduced and nontreated cells using one-way ANOVA, Bonferroni test. \#\#\# $<<0.001$ versus nontransduced cytokine-treated cells using one-way ANOVA, Bonferroni test.

Bcl-2 could protect the cells against FCCP-induced cell death. The protonophore FCCP is able to collapse the proton gradient across the mitochondrial inner membrane, resulting in the complete abolition of the $\Delta \Psi_{\mathrm{m}}$. Cell viability was assessed by XTT assay. Figure 3a shows that a 24-hr exposure to $5 \mu \mathrm{M}$ of FCCP strongly induced cellular death in nontransduced as well as in transduced-but-not-induced cells. Induction of Bcl-2 expression protected against FCCP-induced destruction of RINm5F cells (Fig. 3a). These results demonstrate that adenoviralmediated inducible expression of Bcl-2 counteracts cytokine-induced apoptosis and necrosis. 
(a)

Ainim5F cells

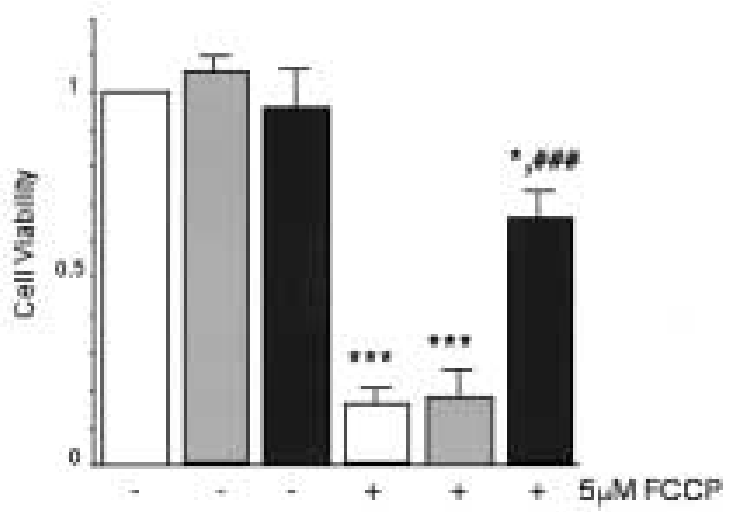

(b)

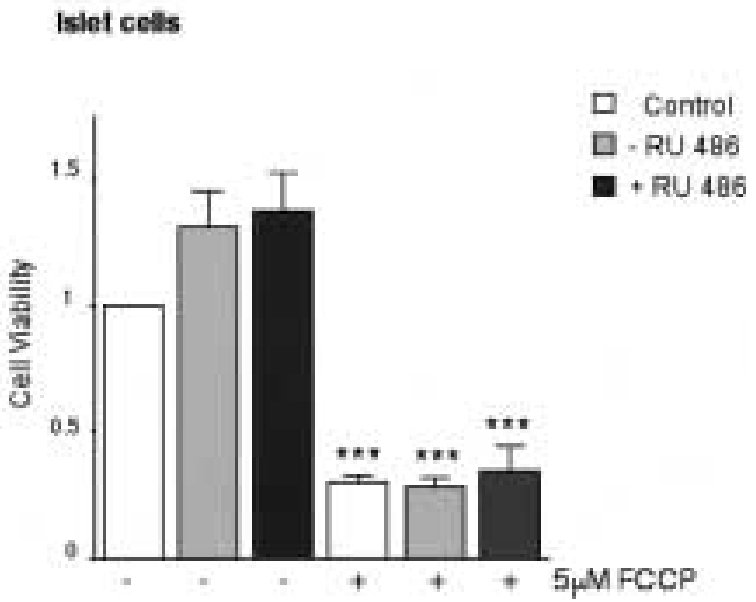

Fig. 3. FCCP-induced cell death and the effect of Bcl-2 expression in RINm5F cells (a) and islet cells (b). Transduced (13 PFU/cell) and nontransduced cells were exposed for $24 \mathrm{hr}$ to $5 \mu \mathrm{M}$ of FCCP and cell viability was assessed by XTT assay. Colorimetric values are normalized to the reading of nontransduced, nontreated cells. Results are mean \pm SEM of eight separate experiments. ${ }^{* * *} p<0.001$ when comparing vs. nontransduced and non-treated cells using one-way ANOVA, Bonferroni test. \#\#\#p<0.001 versus nontransduced cytokinetreated cells using one-way ANOVA, Bonferroni test.

Effect of Bcl-2 Overexpression on Cytokine- and FCCPInduced Mitochondrial Membrane Depolarization in RINm5F Cells

Previous studies have shown that $\Delta \psi_{\mathrm{m}}$ disruption may be an early mitochondrial event leading both to apoptosis and some forms of necrosis (5). Therefore, cytokines and the mitochondrial uncoupler FCCP were used in the experiments described here to determine whether Bcl-2 overexpression acts by modulating the mitochondrial membrane potential. Changes in mitochondrial membrane potential were monitored by flow cytometric determination of the fluorescence emission shift $(530-585 \mathrm{~nm})$ of the mitochondrial probe JC-1. In line with previous reports (20), the cytokine combination IL- $1 \beta$, TNF- $\alpha$, and IFN- $\gamma$ induced a significant reduction in JC-1 585/530 nm fluorescence ratio in RINm5F (a)

HII m5F cells

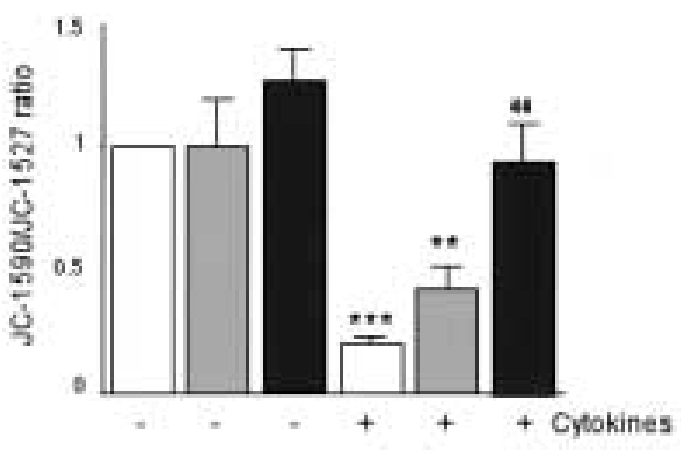

(b)

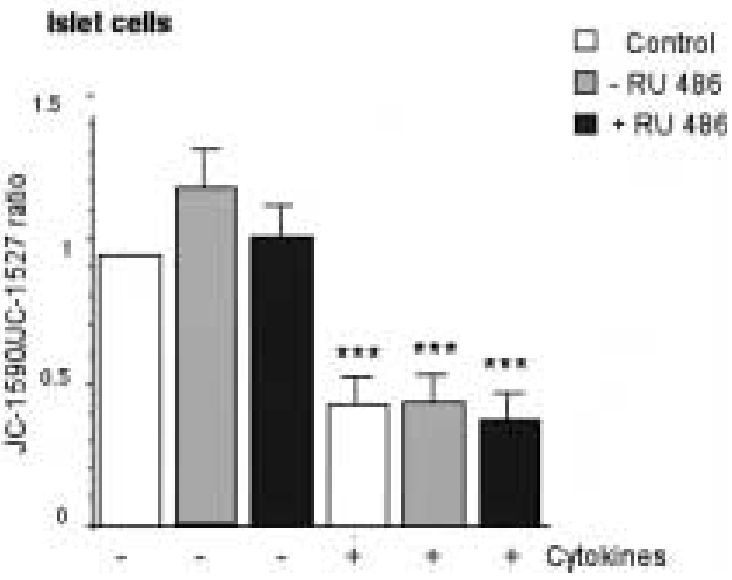

Fig. 4. Effects of cytokines and Bcl-2 expression on JC-1 $\mathrm{J}$-aggregate fluorescence in RINm5F cell (a) and islet cells (b). Cells were exposed to cytokines as described in Figure 2. followed by staining with $10 \mu \mathrm{M}$ of JC-1 and flow cytometry. Data are expressed as the $585 / 530 \mathrm{~nm}$ fluorescence ratio normalized to the reading of control (nontransduced, nontreated) cells. Results are mean \pm SEM of six separate experiments. ${ }^{* *} p<0.005$ when comparing versus nontransduced and nontreated cells using one-way ANOVA, Bonferroni test. $\# \# p<0.005$ when comparing versus nontransduced cytokinetreated cells using one-way ANOVA, Bonferroni test.

cells (Fig. 4a). In addition, Bcl-2 overexpression completely protected against cytokine- as well as FCCP-induced dissipation of the mitochondrial membrane in RINm5F cells (Fig. 4a).

Our observations suggest that induction of cellular death by cytokines and protonophores correlates with the reduction in $\Delta \Psi_{\mathrm{m}}$ and that the ability of Bcl-2 to prevent cell death is related to its mitochondrion-stabilizing activity.

Effect of Bcl-2 Overexpression on Cytokine- and

Because the progesterone-induced adenoviral system proved to have a high efficiency in transducing cells from dispersed rat islets, we investigated the protective effect of Bcl-2 against cytokine- and FCCPinduced death in this cell type. A 6-day incubation of 
islet cells with IL- $1 \beta$, TNF- $\alpha$, and IFN- $\gamma$ resulted in islet cell necrosis as assessed by fluorescence microscopy analysis (results not shown). Bcl-2 overexpression was unable to protect against islet cell death (Fig. 2b). Moreover, FCCP-induced cytotoxicity at $24 \mathrm{hr}$ of exposure was not prevented by Bcl-2 transduction in islet cells (Fig. 3b).

Effect of Bcl-2 Overexpression on Cytokine- and FCCP-Induced Mitochondrial Membrane Depolarization in Islet Cells

Similar to the mechanisms involved in cytokineinduced toxicity in RINm5F cells, the combination

(a)

AINm5F cells

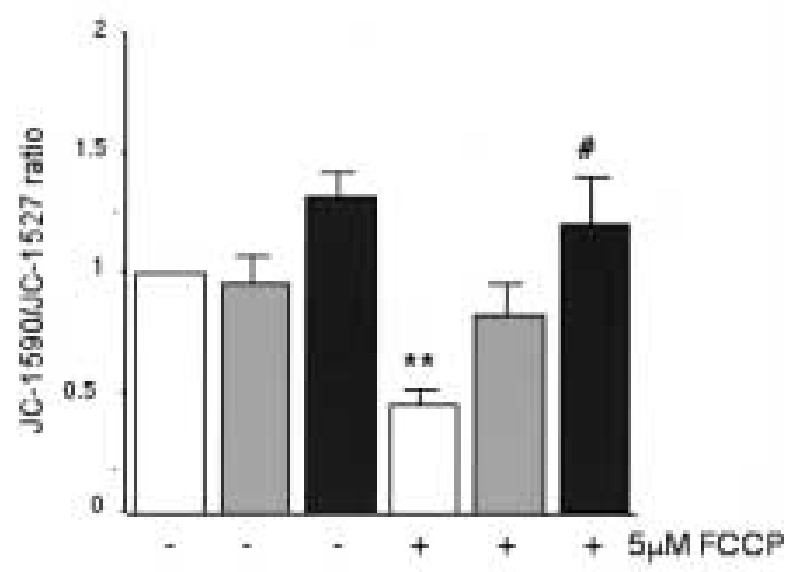

(b) Islet cells

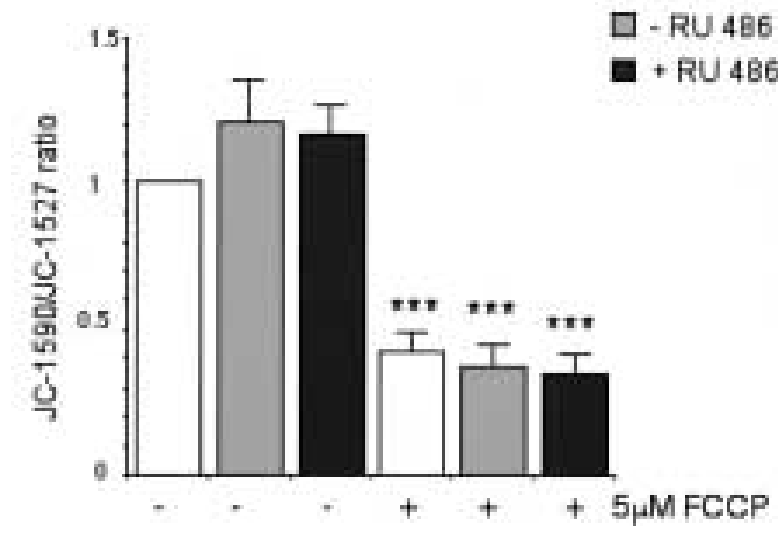

Fig. 5. Effects of FCCP and Bcl-2 expression on JC-1 Jaggregate fluorescence in RINm5F cells (a) and islet cells (b). Cells were exposed for $24 \mathrm{hr}$ to $5 \mu \mathrm{M}$ of FCCP, followed by staining with $10 \mu \mathrm{M} \mathrm{JC}-1$ and flow cytometry. Data are expressed as the $585 / 530 \mathrm{~nm}$ fluorescence ratio normalized to the reading of control (nontransduced, nontreated) cells. Results are mean \pm SEM of six separate experiments. ${ }^{* *} p<0.005$ when comparing versus nontransduced and nontreated cells using one-way ANOVA, Bonferroni test. \#p $<0.05$, when comparing versus nontransduced cytokine-treated cells using one-way ANOVA, Bonferroni test. (a)

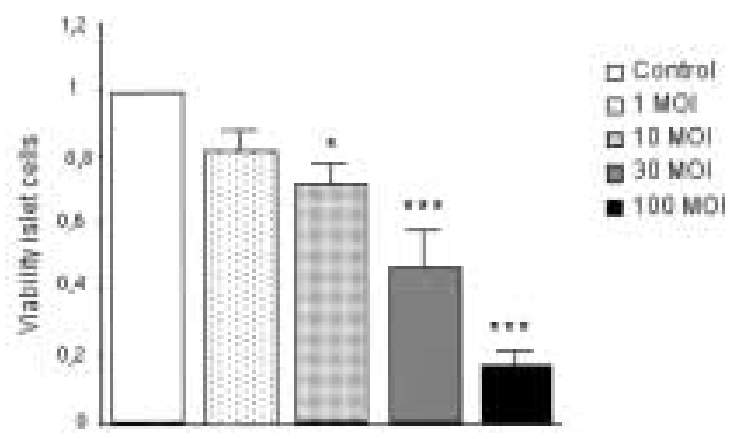

(b)

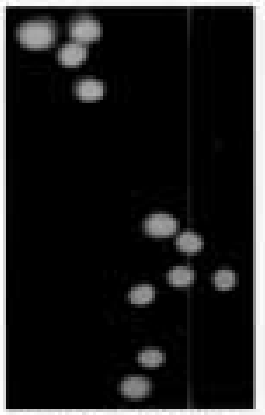

Control islat tels

(c)

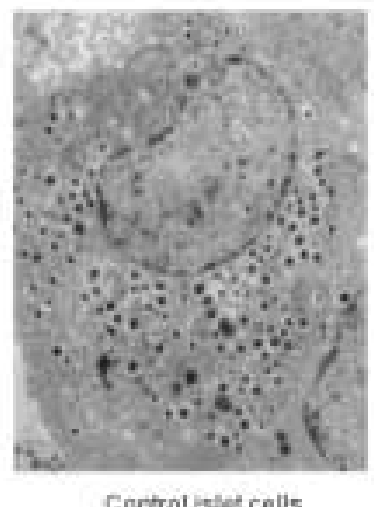

Control istet cells
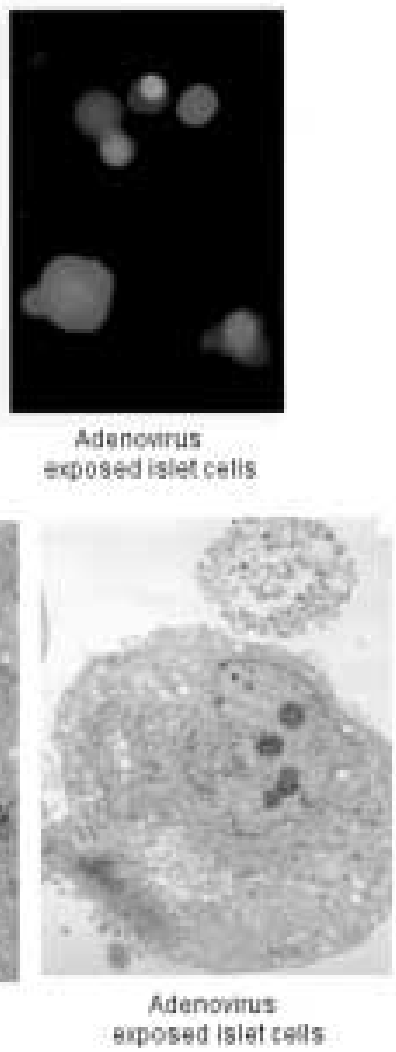

Fig. 6. Effects of adenoviral exposure on islet cell viability. Cells were transduced with different concentrations of adenoviral vector AdCMVProg for $60 \mathrm{~min}$ at $37^{\circ} \mathrm{C}$ and cell viability was assessed 7 days postinfection. Cells were cultured in the absence of RU 486. (a) XTT assay. Individual colorimetric readings are normalized to the value of nontransduced, nontreated cells. Results are mean \pm SD of eight separate experiments. (b) Micrographs showing bisbenzimide/propidium iodide fluorescence of control and adenovirus-exposed (30 PFU/cell) cells. Nuclear blue bisbenzimide staining reflects viable cells, whereas red propidium/iodide staining reflects necrotic cells. (c) Electron microscopy studies on control and adenovirus exposed (30 PFU/cell) cells. $\beta$-Cell necrosis is characterized by vacuolization and the loss of both plasma membrane and nuclear membrane integrity.

IL- $1 \beta$, TNF- $\alpha$, and IFN- $\gamma$ promoted the disruption of the mitochondrial membrane potential in islet cells (Fig. 4b) as assessed by flow cytometry analysis of JC-1 fluorescence. However, adenoviral-induced 
Bcl-2 expression did not prevent cytokine- or FCCPinduced $\Delta \Psi_{\mathrm{m}}$ reduction in this cell type (Figs. $4 \mathrm{~b}$ and $5 \mathrm{~b}$ ). These observations suggest that the failure of Bcl-2 overexpression to prevent cytokine- and FCCP-induced toxicity in islet cells correlates with its lack of efficiency in stabilizing the mitochondrial membrane potential.

\section{Analysis of Cell Viability in Adenoviral-Transfected Islets}

Because Bcl-2 overexpression did not protect islet cells against cytokine- and FCCP-induced $\Delta \Psi_{\mathrm{m}}$ depolarization and cell death, we addressed the question of whether this failure was due to adenoviralinduced toxicity. From XTT-based cell viability assays, we found that transduction of dispersed islet cells for $60 \mathrm{~min}$ at 10 MOI significantly diminished the viability at day 7 following the transduction procedure, and that cell death induced by adenoviral vector occured in a dose-dependent fashion (Fig. 6a). At 2 days following the transduction, there was no cytotoxic effect of the virus (results not shown). Fluorescence microscopy analysis after double staining with bisbenzimide/propidium idodide indicated that viral exposure promoted islets cell necrosis (Fig. 6b). To confirm this result, islet cell morphologic damage was further assessed by electron microscopy. As shown in Figure 6c, adenoviral infection of rat pancreatic islet cells resulted in necrosis evidenced by the loss of both plasma membrane and nuclear membrane integrity, lack of chromatin condensation or fragmentation, as well as vacuolization and swelling of the mitochondrial matrix.

\section{Discussion}

Cytokines may be important mediators of $\beta$-cell death in autoimmune diabetes $(1,21)$ and the proinflammatory cytokines IL- $1 \beta$, TNF- $\alpha$, and IFN- $\gamma$ have been reported to induce destruction of $\beta$-cells in rodent (22) and human islets (23), both by apoptosis and necrosis (4). Previous studies have shown that targeting the cell death pathway by overexpressing the anti-apoptotic gene bcl-2 can exert a cytoprotective effect in several insulin-producing cell types $(10,15,23)$. Therefore, bcl-2 gene therapy has the potential to protect $\beta$-cells in pancreatic islets, or islets grafts, against immune-mediated damage in type 1 diabetes.

Owing to their high capacity of infecting a wide variety of cell types including postmitotic cells, adenoviral vectors have become an attractive tool for gene transfer in $\beta$-cells. However, viral infection and a subsequent constitutive and high gene expression may interfere with signaling systems in the cell and/or lead to cellular toxicity (24). To circumvent such drawbacks, several improved regulatory systems based on adenoviral vectors have been recently developed with the goal of achieving a safe gene delivery and a controlled gene expression into the target cells (25).
Here we used the progesterone antagonist RU 486-regulated adenoviral system $(16,26)$ for the induction of the anti-apoptotic gene bcl-2 in RINm5F cells and rat pancreatic islet cells to investigate its potential as a tool for gene therapy protocols. This is, to our knowledge, the first time an inducible adenoviral system has been evaluated for $\beta$-cell transduction purposes.

Earlier studies have shown that rat pancreatic islets can be efficiently transfected by replicationdeficient adenoviral vectors $(14,27)$. In line with these results, we found that our system induced Bcl-2 overexpression in more than $45 \%$ of RINm5F cells and in more than $70 \%$ of islet $\beta$-cells. Previous observations suggested that induction of high levels of another member of Bcl-2 family, the anti-apoptotic protein $\mathrm{Bcl}-\mathrm{x}_{\mathrm{L}}$, may interfere with the mitochondrial signal for insulin secretion (28). Therefore, an attractive feature of the inducible system described here is that it allows efficient control over the timeperiod and the levels of gene expression. At a first regulatory level, increasingly higher concentrations of adenoviruses resulted in a corresponding increase of Bcl-2 expression. Furthermore, in our system, the basal level of Bcl-2 expression, in the absence of the inducer, was low in pancreatic islets and undetectable in RINm5F cells. At a viral concentration of $10 \mathrm{PFU} / \mathrm{cell}$, addition of $1 \mathrm{ng} / \mathrm{ml}$ of the inducer resulted in a maximal induction of protein expression. This concentration needed for activation is 1000 -fold lower than that required for RU 486 to act as an endogenous progesterone and glucocorticoid antagonist (26). This observation, together with the low basal activity and dose-responsive transcriptional inducibility suggests that this system may be used as an efficient gene transfer tool for the study of $\beta$ cell destruction in autoimmune diabetes.

Transfection of $\beta$-cell lines $(10,29)$ and islet cells $(14,15,23)$ with the anti-apoptotic gene bcl-2 has been reported to protect cells against cytokineinduced apoptosis. In our systems, cellular death was prevented by Bcl-2 adenoviral-induced overexpression only in RINm5F cells; no protection was seen in rat islet cells. It has been shown that, at least in some instances, apoptosis and necrosis share a molecular event of MPT, which involves the opening of a multiprotein complex pore located at the contact site between the inner and outer mitochondrial membrane (5), and the consecutive dissipation of the mitochondrial membrane potential $\left(\Delta \Psi_{\mathrm{m}}\right)$. We have previously shown that cytokines induce depolarization of the mitochondrial membrane potential in RINm5F cells as an early step of the cell death pathway (20). The present study extends these observations for dispersed rat pancreatic islet cells. However, although Bcl-2 expression blocked $\Delta \Psi_{\mathrm{m}}$ reduction in RINm5F cells, cytokineinduced dissipation of the mitochondrial membrane was not affected by the induction of Bcl-2 in islet cells. 
To further investigate the relation between cell death prevention by Bcl-2 and its activity at the mitochondrial membrane, we studied the effect of the protonophore FCCP on both RINm5F and islet cells as well as the effect of Bcl-2 overexpression on these cells. This protonophore causes dissipation of the proton gradient across the inner mitochondrial membrane, thereby uncoupling the process of oxidative phosphorylation from ATP synthesis. Other studies have shown that exposure to protonophores induces cellular death, which can be prevented by Bcl-2 (30,31). In our system, cell survival measurements indicate that exposure to FCCP over $24 \mathrm{hr}$ induces a severe toxicity in both cell types, also reflected by the disruption of the mitochondrial membrane potential. Similar to cytokine-induced toxicity, Bcl-2 was able to overcome the effect of FCCP on $\Delta \Psi_{\mathrm{m}}$ and prevent cellular death, but only in RINm5F cells. All these results show that reduction in $\Delta \Psi_{\mathrm{m}}$ induced by cytokines or FCCP correlates with induction of cellular death and suggest that Bcl-2 anti-apoptotic action is strongly related to its mitochondrion-stabilizing effect.

Our experiments performed in RINm5F cells show a fully functional RU 486-induced Bcl-2 protein, which has the capacity to block depolarization of the mitochondrial membrane induced both by FCCP and cytokines and prevent the associated cellular death. However, no protective effect was seen when Bcl-2 overexpressing islet cells were treated with cytokines or FCCP. We therefore addressed the question of whether this difference was due to an increased sensitivity of pancreatic islet cells to viral toxicity. In the present study, the adenoviral exposure was found to induce a significantly diminished cell viability already at a viral concentration of 10 PFU/cell of viral concentration as assessed by XTTbased and fluorescence microscopy assays. This pronounced adenoviral cytotoxicity might be induced directly by residual expression of viral proteins or via the accumulation of double-stranded RNA in the cytoplasm of infected cells $(32,33)$. We consider it unlikely that the cytotoxic effect was due to expression of the AdCMVProg virus chimeric transactivator protein, because this fusion protein is considered to be inert in the absence of inducer (RU 486). Nevertheless, we have recently initiated a comparison of the progesterone antagonist inducible adenoviral vector with other noninducible vectors to establish whether the presently observed toxicity is specific to this particular vector or not.

It seems apparent that adenoviruses induce cells to die via multiple pathways, some of which may result in apoptosis; others could promote necrosis (32). In this regard, apoptotic and some types of necrotic processes are regulated at the mitochondrial level by proteins belonging to Bcl-2 family, and recent studies suggested that coexpression of bcl-2 gene may have the potential to "cytoprotect" the adenovirus vector-infected cells $(34,35)$. In our hands, cell viability and morphologic studies show that adenoviral-induced cytotoxicity in islet cells results mainly in necrosis. Although cytokine addition may further modulate the death pathway (36), our observations suggest that viral-induced cytotoxicity is the main trigger of islet cell destruction and Bcl-2 overexpression failed to prevent it. It is possible that this adenoviral-induced necrotic pathway in pancreatic islet cells might bypass the mitochondrial permeability transition event, which will make the overexpression of Bcl-2 insufficient to support cell survival. In this context, it should be noted that transgenic mice with $\beta$-cell specific Bcl-2 overexpression do not display increased $\beta$-cell survival in response to autoimmune attack or to the $\beta$-cell toxin streptozotocin (37). It is not clear why we presently observe a lack of protection of Bcl-2 and a cytotoxic effect of adenoviral vectors, whereas other investigators have not $(14,15,23)$. One possible explanation may be that dispersed islet cells were transduced in the present investigations and only whole islets in previous studies. In whole islets, it may be that very few adenoviral particles reach the center of the islet, leading to a weaker cytotoxic effect in the centrally located $\beta$-cells.

In summary, we find that transduction of rat pancreatic islet cells using the RU 486-inducible adenoviral system can achieve an efficient control of gene transfer at relatively low doses of the adenoviral vector. However, in vitro prolonged culture, after cell/virus incubation, reveals adenoviralinduced islet cell necrosis, which is not counteracted by Bcl-2 overexpression. Our results suggest that establishing safe therapeutic windows for each virus/cell system studied is an important prerequisite for the successful use of adenoviral vectors in $\beta$-cell research. Finally, the characterization of the mechanisms behind adenoviral vector-induced $\beta$-cell death might generate important clues for an understanding of the pathogenesis of type 1 diabetes.

\section{Acknowledgments}

We gratefully acknowledge the excellent technical assistance of Ing-Marie Mörsare and Ing-Britt Hallgren. We also thank Prof Gotfried Roomans and Marianne Ljungkvist for helping us with electron microscopy studies. This work was supported in part by Swedish Medical Research Council Grants (72P-12995, 12X-11564, 12X-109), the Swedish Diabetes Association, the Nordic Insulin Fund, the Juvenile Diabetes Foundation International, and the Family Ernfors Fund.

\section{References}

1. Mandrup-Poulsen T. (1996) The role of interleukin-1 in the pathogenesis of IDDM. Diabetologia 39: 1005-1029.

2. Eizirik DL, Pavlovic D. (1997) Is there a role for nitric oxide in $\beta$-cell dysfunction and damage in IDDM? Diabetes Metab. Rev. 13: 293-308. 
3. Mauricio D, Mandrup-Poulsen T. (1998) Apoptosis in the pathogenesis of IDDM: a question of life and death. Diabetes 47: 1537-1543.

4. Saldeen J. (2000) Cytokines induce both necrosis and apoptosis via a common Bcl-2 inhibitable pathway in rat insulinproducing cells. Endocrinology 141: 2003-2010.

5. Kroemer G, Dallaporta B, Resche-Rigon M. (1998) The mitochondrial death/life regulation in apoptosis and necrosis. Annu. Rev. Physiol. 60: 619-642.

6. Kluck RM, Bossy-Wetzel E, Green DR, Newmeyer DD. (1997) The release of cytochrome $c$ from mitochondria: a primary site for Bcl-2 regulation of apoptosis. Science 275: 1132-1136.

7. Yang J, Liu X, Bhalla K, et al. (1997) Prevention of apoptosis by Bcl-2: release of cytochrome $c$ from mitochondria blocked. Science 275: 1129-1132.

8. Xia Z, Lundgren B, Bergstrand A, DePierre J, Nässberger L. (1999) Changes in the generation of reactive oxygen species and in mitochondrial membrane potential during apoptosis induced by antidepressants imipramide, clomipramide and citalopram and the effects on these changes by Bcl-2 and BclX(L). Biochem. Pharmacol. 57: 1199-1208.

9. Ju Q, Edelstein D, Brendel MD, Brandhorst D, Bretzel RG, Brownlee M. (1998) Transduction of non-dividing adult human pancreatic beta cells by an integrating lentiviral vector. Diabetologia 41: 736-739.

10. Dupraz P, Rinsch C, Pralong WF, et al. (1999) Lentivirus-mediated Bcl-2 expression in $\beta$ TC-tet cells improves resistance to hypoxia and cytokine-induced apoptosis while preserving in vitro and in vivo control of insulin secretion. Gene Ther. 6: $1160-1169$.

11. Flotte T, Agarwal A, Wang J, et al. (2001) Efficient ex vivo transduction of pancreatic islet cells with recombinant adenoassociated virus vectors. Diabetes 50: 515-520.

12. Shifrin AL, Aurrichio A, Yu QC, Wilson J, Raper SE. (2001) Adenoviral-mediated insulin gene transfer in the mouse pancreas corrects streptozotocin-induced hyperglycemia. Gene Ther. 19: 1480-1489.

13. Heimberg H, Heremans $Y$, Jobin C, et al. (2001) Inhibition of cytokine-induced NF-kappaB activation by adeno-virus mediated expression of NF-kappaB super-repressor prevents beta-cell apoptosis. Diabetes 50: 2219-2224.

14. Contreras JL, Bilbao G, Smyth CA, et al. (2001) Cytoprotection of pancreatic islets before and soon after transplantation by gene transfer of the antiapoptotic Bcl-2 gene. Transplantation 71: 1015-1023.

15. Contreras JL, Bilbao G, Smyth C, et al. (2001) Gene transfer of the BCL-2 gene confers cytoprotection to isolated adult porcine pancreatic islets exposed to xenoreactive antibodies and complement. Surgery 130: 166-174.

16. Molin M, Shoshan MC, Öhman-Forslund K, Linder S, Akusjärvi G. (1998) Two novel adenovirus systems permitting regulated protein expression in gene transfer experiments. J. Virol. 72: 8358-8361.

17. Andersson A. (1978) Isolated mouse pancreatic islets in culture: effects of serum and different culture media on the insulin production of the islets. Diabetologia 14: 397-404.

18. Saldeen J, Welsh N. (1998) Nicotinamide-induced apoptosis in insulin producing cells is associated with cleavage of poly(ADP-ribose)polymerase. Mol. Cell. Endocrinol. 139: 99107.

19. Mathur A, Hong Y, Kemp BK, Barrientos AA, Erusalimsky JD. (2000) Evaluation of fluorescent dyes for the detection of mitochondrial membrane potential changes in cultured cardiomyocytes. Cardiovasc. Res. 46: 126-138.

20. Barbu A, Welsh N, Saldeen J. (2002) Cytokine-induced apoptosis and necrosis are preceded by disruption of the mitochondrial membrane potential $\left(\Delta \Psi_{\mathrm{m}}\right)$ in pancreatic RINm5F cells: prevention by Bcl-2. Mol. Cell. Endocrinol. 190: 72-85.

21. Rabinovitch A, Suarez-Pizon WL. (1998) Cytokines and their roles in pancreatic islet $\beta$-cell destruction and insulin-dependent diabetes mellitus. Biochem. Pharmacol. 55: 1139-1149.

22. Liu D, Pavlovic D, Chen MC, Flodström M, Sandler S, Eizirik DL. (2000) Cytokines induce apoptosis in $\beta$-cells isolated from mice lacking the inducible isoform of nitric oxide synthase $\left(\mathrm{iNOS}^{-/}\right)$. Diabetes 49: 1116-1122.

23. Rabinovitch A, Suarez-Pizon W, Strynadka K, et al. (1999) Transfection of human pancreatic islets with an anti-apoptotic gene (Bcl-2) protects $\beta$-cells from cytokine-induced destruction. Diabetes 48: 1223-1229.

24. Weber M, Deng S, Kucher T, Shaked A, Ketchum RG, Brayman K. (1997) Adenoviral transfection of isolated pancreatic islets: a study of programmed cell death (apoptosis) and islet function. J. Surg. Res. 69: 23-32.

25. Harvey DM, Kaskey CT. (1998) Inducible control of gene expression: prospects for gene therapy. Curr. Opin. Chem. Biol. 2: 512-518.

26. Wang Y, O'Malley BW Jr, Tsai SY, O'Malley BW. (1994) A regulatory system for use in gene transfer. Proc. Natl. Acad. Sci. U. S. A. 91: 8180-8184.

27. Leibowitz J, Beatti GM, Kafri T. (1999) Gene transfer to human pancreatic endocrine cells using viral vectors. Diabetes 45: 745 .

28. Zhou YP, Pena JC, Roe MW, et al. (2000) Overexpression of $\mathrm{Bcl}-\mathrm{X}(\mathrm{L})$ in $\beta$-cells prevents cell death but impairs mitochondrial signal for insulin secretion. Am. J. Physiol. Endocrinol. Metab. 278: E340-E351.

29. Iwahashi H, Hanafusa T, Eguchi Y, et al. (1996) Cytokine-induced apoptotic cell death in a mouse pancreatic beta-cell line: inhibition by Bcl-2. Diabetologia 39: 530-536.

30. Dyspersin G, Nuydens R, Connors R, Borgers M, Geerts H. (1999) Bcl-2 protects against FCCP-induced apoptosis and mitochondrial membrane potential depolarization in $\mathrm{PC} 12$ cells. Biochem. Biophys. Acta 1428: 357-371.

31. Zamzami N, Brenner C, Marzo I, Susin A, Kroemer G. (1998) Subcellular and submitochondrial mode of action of BCL-2like oncoproteins. Oncogene 16: 2265-2282.

32. Braithwaite AW, Russell IA. (2001) Induction of cell death by adenoviruses. Apoptosis 6: 359-370.

33. Jacobs BL, Langland JO. (1996) When two strands are better than one: the mediators and modulators of the cellular responses to double-stranded RNA. Virology 219: 339-349.

34. Bilbao G, Contreras JL, Zhang HG, et al. (1999) Adenovirusmediated gene expression in vivo is enhanced by the antiapoptotic Bcl-2 gene. J. Virol. 73: 6992-7000.

35. Lieber A, He CY, Meuse L, Himeda C, Wilson C, Kay MA. (1998) Inhibition of NF- $k$ B activation in combination with Bcl-2 expression allows for persistence of first-generation adenovirus in the mouse liver. J. Virol. 72: 9267-9277.

36. Scarim AL, Arnush M, Blair LA, et al. (2001) Mechanisms of $\beta$-cell death in response to double-stranded (ds) RNA and Interferon- $\gamma$ : dsRNA-dependent protein kinase apoptosis and nitric oxide-dependent necrosis. Am. J. Pathol. 159: 273-283.

37. Allison J, Thomas H, Beck D, et al. (2000) Transgenic overexpression of human Bcl-2 in islet $\beta$ cells inhibits apoptosis but does not prevent autoimmune destruction. Int. Immunol. 12: 9-17. 